
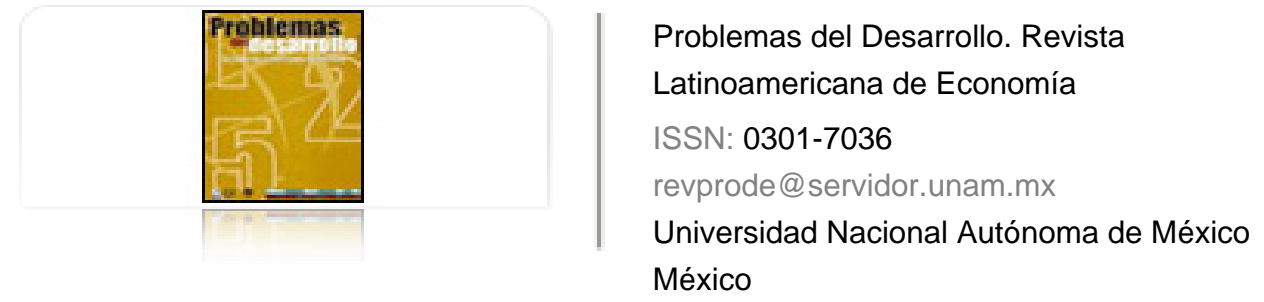

Pinazo, Germán; Piqué, Pilar

Desarrollo latinoamericano en el marco de la globalización

Problemas del Desarrollo. Revista Latinoamericana de Economía, vol. 42, núm. 166, julio-septiembre, 2011, pp. 7-35

Universidad Nacional Autónoma de México

Distrito Federal, México

Disponible en: http://www.redalyc.org/articulo.oa?id=11819777002

- Cómo citar el artículo

- Número completo

- Más información del artículo

Página de la revista en redalyc.org

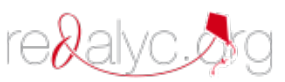

Sistema de Información Científica

Red de Revistas Científicas de América Latina, el Caribe, España y Portugal Proyecto académico sin fines de lucro, desarrollado bajo la iniciativa de acceso abierto 


\title{
DesarRollo LATINOAMERICANO EN EL MARCO DE LA GLOBALIZACIÓN
}

\author{
Germán Pinazo* y Pilar Piqué**
}

Fecha de recepción: 13 de diciembre de 2010. Fecha de aceptación: 19 de marzo de 2011.

\begin{abstract}
RESUMEN
Desde hace varios años que el pensamiento heterodoxo latinoamericano en lo relativo a la problemática del desarrollo se encuentra atravesado por profundas discusiones. En este marco, el primer objetivo de este trabajo es repasar críticamente las ideas centrales de lo que entendemos es la formación de un nuevo consenso sobre la temática, que bajo el nombre de neoestructuralismo o neodesarrollismo, pretende ser tanto una crítica al recetario neoliberal, como una superación del viejo desarrollismo. Un segundo objetivo es vincular este repaso con el análisis de las transformaciones del sector automotriz argentino. Con ello se busca mostrar la necesidad de retomar el método histórico como herramienta para reconocer las posibilidades de desarrollo de los países latinoamericanos en el marco de la división internacional del trabajo.
\end{abstract}

Palabras clave: Desarrollo Económico, Estructuralismo, Neoestructuralismo, segmentación productiva, industria automotriz.

\section{LATIN AMERICAN DEVELOPMENT IN THE FRAMEWORK OF GLOBALIZATION}

\begin{abstract}
Heterodox Latin American thinking on the development problematic has for several years been engaged in deep debate. Within this framework, the first objective of our study is to review critically the central ideas of what we understand to be the formation of a new consensus on the question known as neo-structuralism or neo-developmentalism, which seeks to be both a criticism of the neo-liberal prescription and an improvement on the old developmentalism. A second objective is to link this review with the analysis of transformations in Argentina's auto industry. In this way, we seek to show the need to return to the historical method as a way of recognizing the possibilities for development in the Latin American countries within the framework of the international division of labor. Key words: Economic Development, Structuralism, Neo-structuralism, productive segmentation, auto industry.

\footnotetext{
* Investigador-Docente de la Universidad Nacional de General Sarmiento (UNGs) y de la Fundación de Investigaciones Sociales y Políticas (FISyp).

* Investigadora-Docente de la Universidad Nacional de General Sarmiento (UNGs).
} 


\section{DÉVELOPPEMENT LATINO-AMÉRICAIN DANS LE CADRE DE LA GLOBALISATION.}

\section{Résumé}

Depuis plusieurs années, la pensée hétérodoxe latino-américaine relative à la problématique du développement est traversée par de profondes discussions. Dans ce cadre, le premier objectif de ce travail est de repasser avec un œil critique les idées centrales de ce que nous entendons comme la formation d'un nouveau consensus sur ce thème, qui, sous le nom de néo-structuralisme ou modèle de néo-développement, prétend être autant une critique de la recette néolibérale qu'un dépassement de l'ancien modèle de développement. Un second objectif consiste à relier cette révision avec l'analyse des transformations du secteur automobile argentin. De cette manière, il est tenté de démontrer la nécessité de reprendre la méthode historique comme outil pour reconnaître les possibilités de développement des pays latino-américains dans le cadre de la division internationale du travail.

Mots clés : développement économique, structuralisme, néo-structuralisme, segmentation productive, industrie automobile.

\section{DESENVOLVIMENTO LATINO-AMERICANO NO MARCO DA GLOBALIZAÇÃO. \\ Resumo}

Há vários anos o pensamento heterodoxo latino-americano no relativo à problemática do desenvolvimento se encontra atravessado por profundas discussóes. Neste marco, o primeiro objetivo deste trabalho é repassar criticamente as idéias centrais do que entendemos ser a formação de um novo consenso sobre a temática, que sob o nome de neo-estruturalismo ou novo-desenvolvimentismo, pretende ser tanto uma critica ao receituário neoliberal, como a superação do velho desenvolvimentismo. Um segundo objetivo é vincular esse repasso com a analise das transformaçóes do setor automotriz argentino. Com isso, se busca mostrar a necessidade de retomar o método histórico como ferramenta para reconhecer as possibilidades de desenvolvimento dos países latino-americanos no marco da divisão internacional do trabalho.

Palavras-chave: Desenvolvimento econômico, Estruturalismo, Neo-estruturalismo, segmentação produtiva, indústria automotriz.

\section{在全球化的框架下对拉美发展的评论}

小结

几年来，关于拉美发展的异端思想经历过几次深刻的争论。在这种框架下， 此工作的第一个目标就是评判性的回顾一下我们所理解的中心思想，这样才 能形成对此话题的一个新的共识, 此话题是在新结构主义和新发展主义的名 义下, 作为一种对就发展主义的超越, 力图成为一种对新自由主义方式的批 判。第二个主要目的是将这种回顾和阿根廷机动行业变化的分析联系在一 起。通过此联系, 寻找重新采纳历史方法的需要, 这种方法作为一种工具以 此来发掘在国际劳动分工的框架下拉丁美洲国家发展的可能性。 关键词：经济发展，结构主义，新结构主义，生产力部分，机动工业 


\section{INTRODUCCIÓN}

Los comienzos de la década del setenta fueron el escenario de una profunda transformación en el proceso de producción mundial. Más específicamente, una serie de desarrollos tecnológicos encaminados hacia la automatización de numerosos segmentos de los procesos productivos, el desarrollo de la informática y las telecomunicaciones -especialmente en el seno de la industria electrónica-, reconfiguraron los procesos de organización del trabajo a escala planetaria

Este proceso, mientras parece haber supuesto un cambio en la inserción de los países periféricos en la división internacional del trabajo, condujo a una parte importante del pensamiento heterodoxo latinoamericano a replantear aquello que había sabido ser su norte en materia de política económica: la industrialización por sustitución de importaciones. Así, fue formándose un nuevo consenso teórico que, bajo el nombre de neoestructuralismo o neodesarrollismo, ${ }^{1}$ nació como una crítica al recetario neoliberal y como una superación del viejo desarrollismo. Esquemáticamente, dicho consenso señala que la mejor estrategia para el desarrollo en países periféricos radica en una industrialización orientada a la exportación que haga eje en el aprovechamiento de las ventajas que surgen del nuevo escenario de globalización productiva a partir del estímulo a la innovación tecnológica.

En este marco, este trabajo tiene la intención de aportar al debate acerca de las estrategias para el desarrollo latinoamericano. En primer lugar, a partir de la formulación de un repaso crítico por lo que consideramos son las ideas centrales de este nuevo consenso en torno a las posibilidades y formas de inserción en este nuevo esquema mundial, que contribuyan al desarrollo de los países de la periferia latinoamericana. En segundo lugar, intentaremos vincular este repaso con el análisis de una de las transformaciones más importantes que ha sufrido el sector industrial argentino en los últimos 50 años: el de su sector automotriz. Lo que se busca, tanto en uno como en otro apartado, es mostrar la necesidad de retomar uno de los pilares del pensamiento crítico estructuralista de la primera

1 Entendemos que la utilización de nombres para definir un debate de ideas cuyos límites son difusos, puede acarrear ciertos inconvenientes. No obstante, entendemos que es sumamente útil a los fines expositivos de este trabajo, y que dichas denominaciones son utilizadas por autores y textos que, como veremos, son una referencia importante del pensamiento heterodoxo latinoamericano en materia económica (Bielchowsky, 2009; CEPAL, 2009; Bresser-Pereira, 2007; Romo, 2007; Nahón et al, 2006). 
época (que, a nuestro entender, fue progresivamente dejado de lado en este nuevo consenso): el del método histórico como herramienta para aprehender los particulares condicionantes que limitan el desarrollo de los países latinoamericanos en el marco de la división internacional del trabajo.

\section{SEGMENTACIÓN INTERNACIONAL DE LA PRODUCCIÓN, REDEFINICIONES TEÓRICAS, DISPUTAS Y CONSENSOS}

Si bien las transformaciones en el pensamiento económico de Latinoamérica están atravesadas por una multiplicidad de factores complejos, parece existir uno que ocupa un lugar excluyente como motor de las nuevas discusiones teóricas: la globalización productiva. En palabras de Bresser-Pereira (2007: 117): "las diferencias entre el desarrollismo de los 50 y el nuevo desarrollismo se explican, en primer lugar, por los cambios ocurridos en el contexto capitalista mundial, que pasó de los 'años dorados' a la actual fase de globalización'.

En efecto, desde distintas corrientes teóricas existe un cierto consenso en que estamos asistiendo a una nueva etapa en términos de internacionalización del capital y de la producción industrial debido a que los profundos desarrollos tecnológicos acaecidos durante los últimos cuarenta años (fundamentalmente aquellos vinculados a la informática y al desarrollo en las comunicaciones), aplicados tanto a procesos de producción como de gestión y comercialización, dieron lugar a lo que desde distintas corrientes teóricas se ha denominado como cadenas globales de valor, o procesos de internacionalización de la producción (Kaplinsky, 2005; Arrighi, 1994; Gereffi, 2001; Minian, 2009). En este marco, los distintos eslabones o segmentos que componen la producción de una mercancía pueden ser divididos entre distintos países en función de distintos objetivos e incentivos, que incluyen desde el abastecimiento de mercados regionales hasta el aprovechamiento de recursos naturales así como la búsqueda de una mayor calificación y/o menor costo de la mano de obra, entre otros. A su vez, son grandes empresas trasnacionales dedicadas a la producción manufacturera o a su comercio las que se han convertido en las conductoras de estas cadenas globales de producción e intercambio (Gutman y Gorenstein, 2003, 2009; Gereffi y Korzeniewick, 1994).

Pero si bien existe un relativo consenso en torno al desarrollo de una etapa novedosa en términos de internacionalización de la producción, no lo hay a la hora de analizar sus consecuencias para los países en desarrollo. En palabras de Gereffi (2001: 3): 
Hay una aguda división entre los teóricos que consideran a la globalización ${ }^{2}$ como una restricción de las perspectivas de desarrollo de las naciones no centrales y los que ven los vínculos que implica la globalización, la cual no sólo representa restricciones sino también oportunidades para el avance de los países en desarrollo. Estas diferencias se dan en forma paralela a la controversia que estuvo en boga en la década de los ańos setenta en la teoría del desarrollo entre las perspectivas de la modernización y las de la dependencia.

Esta caracterización del problema nos parece sumamente elocuente, no sólo porque proviene de un autor reconocido de la problemática de la globalización productiva, sino porque inscribe la discusión en un viejo debate en el que los teóricos latinoamericanos dejaron sentados numerosos aportes. En efecto, entre las décadas del cincuenta y el setenta del siglo pasado, el pensamiento crítico latinoamericano desarrolló una serie de planteos que apuntaron a cuestionar el núcleo de la teoría del desarrollo elaborada en los centros de estudio de los países desarrollados. Esquemáticamente, la idea central de la crítica tenía que ver con señalar que el carácter general y apriorístico de las teorías neoclásicas en lo relativo al problema del desarrollo económico (íntimamente ligado con la arbitrariedad de sus supuestos), no prestaba la debida atención a las especificidades de la realidad periférica, asociadas a su particular historia de retraso relativo. Las palabras de Sztulwark (2005: 29) son elocuentes en relación a la ruptura teórica que significó el primer estructuralismo con los métodos de la teoría económica dominante.

Su objeto de estudio es la historia real, y el abordaje no remite directamente a un modelo ideal, sino más bien a los aspectos sociológicos e históricos que subyacen al sistema económico y permiten explicarlo. Tal enfoque suponía una ruptura con el abordaje metodológico de la economía pura que, en términos del lenguaje cepalino, se denominó método histórico estructuralista.

Ahora bien, en un contexto de profundas transformaciones de la región, una parte importante del pensamiento heterodoxo en Latinoamérica experimentó una severa transformación a partir de la década del setenta. La visión crítica del

2 El término "globalización" incluye de manera central la problemática de la internacionalización de la producción. De hecho, Gereffi es un autor destacado en la problemática de las cadenas globales de valor. 
viejo estructuralismo en torno al carácter subordinado del crecimiento económico en la periferia y la necesidad de formular un pensamiento económico autónomo acorde a la problemática específica de la región tendió a perder peso frente a una visión sumamente despolitizada de las transformaciones económicas que, en consonancia con los postulados más profundos de la teoría liberal, el desarrollo pasó a ser un problema del agente individual, en un contexto donde éste tiene las herramientas para aprovechar las ventajas del progreso tecnológico. Así, fueron perdiendo peso categorías como centro y periferia así como el análisis de los condicionantes vinculados a los intereses de las distintas fracciones de clase involucradas y/o a las estructuras de propiedad, frente a una realidad pensada en términos de "agentes" potencialmente homologables y competitivos (Nahon et al, 2006; Casparrino, 2010). ${ }^{3}$ Como sostiene Guillén Romo (2007: 312):

El neoestructuralismo se construye más sobre una crítica de las consecuencias sociales del ajuste que sobre una crítica radical de sus fundamentos teóricos esencialmente neoclásicos y neoliberales (...) En estas condiciones resulta natural que aunque pretenda ser una alternativa al neoliberalismo, el neoestructuralismo latinoamericano termina por compartir con el enfoque neoliberal muchos de sus postulados y análisis. Como señala Eric Mulot, “(...) la escuela cepalina perdió una gran parte de su identidad haciendo suyas teorías (capital humano, crecimiento endógeno) cuyos fundamentos son opuestos a los del estructuralismo.

Siguiendo a Nahón et al (2006: 373), podemos decir que este último periodo del pensamiento latinoamericano en lo relativo a la problemática del desarrollo se ha caracterizado por la pérdida del "carácter fuertemente crítico y cuestionador del pensamiento latinoamericano de la primera hora", y por lo tanto, por "la adopción prácticamente acrítica de las ideas en boga en la agenda internacional". En este sentido, una de las hipótesis de este trabajo es que tanto las estrategias políticas planteadas por el neodesarrollismo, como las rupturas teóricas del neoestructuralismo, deben ser leídas teniendo en cuenta este contexto. Es decir, como señala González Gómez (2009: 4), un contexto de "inexistencia de un esbozo siquiera de un cuerpo teórico apropiado de América Latina en el sistema mundo", que por lo tanto se caracteriza por la repetición, o el intento

3 La CEPAL reconoce el cambio en el contexto económico político en la región, pero considera que "si para algunos ello significó rendirse ante el neoliberalismo, para otros fue una alternativa que permitiría seguir incidiendo en los destinos de la región desde la perspectiva teórico y metodológica de la CEPAL" (Bielchowsky, 2009: 178). 
de adecuación en algunos casos, de las interpretaciones generadas en los centros de investigación de los países desarrollados, en torno a las posibles oportunidades abiertas en el nuevo contexto de globalización productiva. ${ }^{4}$ En este contexto consideramos que debe leerse la renuncia al objetivo histórico y fundamental de desarrollar un sistema industrial más allá de la lógica de las ventajas comparativas como forma de superar la condición periférica (Arceo, 2005: 83), y su reemplazo por una estrategia de desarrollo basada en la idea general de ascenso industrial, íntimamente vinculado al presupuesto de que, en un nuevo escenario de internacionalización productiva, es posible para los agentes económicos de los países en desarrollo aprovechar los nuevos "espacios globales" de negocios (Bielchowsky, 2009; Bresser-Pereira, 2007). La siguiente cita de Gereffi (2001: 27-28; subrayado propio) es útil para reconocer cuál es el razonamiento detrás de este último planteo.

Lo que distingue a la globalización de etapas anteriores en la división internacional del trabajo es, en gran medida, la habilidad de los productores para dividir (geográficamente) el valor de la cadena (...) Esta dispersión global de las cadenas productivas aumenta las oportunidades de los paises en desarrollo de participar y ganar a partir del comercio, ya que éste les proporciona un espacio mayor para especializarse en las etapas de trabajo intensivo del proceso de fabricación de un artículo (...) el ascenso industrial implica cambiar las cadenas productivas de actividades intensivas en mano de obra a actividades económicas intensivas en capital y habilidades, que conlleven aprendizaje organizativo para mejorar la posición de las empresas o las naciones en el comercio internacional y en las redes de producción.

Como señala la cita, la segmentación internacional de la producción puede ser vista como una oportunidad para la periferia en la medida en que las empresas periféricas que participan en etapas de trabajo intensivas del proceso productivo puedan ir aprendiendo y ganando las habilidades necesarias para ascender en los eslabones del proceso productivo global. El desarrollo económico resulta de la capacidad de los agentes económicos de países en desarrollo de promover actividades cada vez más necesarias en estos procesos, apropiándose así de una parte cada vez mayor del valor generado en éstos. En sintonía con este tipo de

4 En sintonía con el planteo de Nahón et al, 2006, González Gómez señala que "la interpretación esencial (sobre el problema general de las nuevas transformaciones industriales) siguió las pautas de las interpretaciones surgidas en los países centrales para situaciones aparentemente similares y existe una gran coincidencia a lo largo de diversos países latinoamericanos" (2009: 2). 
planteos, encontramos que varios autores de este nuevo pensamiento latinoamericano han aceptado la política focalizada de incentivos a la innovación tecnológica en un contexto de apertura comercial y tipo de cambio real competitivo como los pilares fundamentales de cualquier estrategia para el desarrollo económico (Sunkel et al, 2009). ${ }^{56}$

Lo que nos interesa destacar es que concepciones como la anterior en torno a las oportunidades que se derivan de esta nueva división internacional del trabajo sólo pueden ser pensadas en un esquema con las características señaladas anteriormente. Es decir, un esquema que ha abandonado explícitamente las dimensiones sociológicas e históricas en el análisis (Casparrino, 2009) y que, fundamentalmente, ha aceptado aquellos supuestos teórico-metodológicos antes centro de su crítica. ${ }^{7}$ A nuestro modo de ver, la reivindicación del método histórico estaba en sus orígenes íntimamente vinculada con la crítica a la premisa liberal según la cual todos los agentes económicos (o sujetos políticos, según sea el plano de la discusión) tienen las mismas posibilidades de crecimiento o desarrollo. La crítica estructuralista a este postulado radicaba en el reconocimiento de que la historia de retraso relativo de la periferia y los modos específicos en los que ésta se había insertado en la división internacional del trabajo, condicionaban de un modo muy particular su desarrollo. De allí que sus problemáticas no había que buscarlas en una falta de voluntad o capacidad de sujetos individuales, sino en problemas histórico-estructurales que hacen incomparables a los sujetos de formaciones sociales distintas, e impiden la generalización de las recetas económicas.

5 No sólo es posible ver este tipo de análisis en los textos fundamentos del neoestructuralismo, sino que la incorporación "formal" de las teorías de la innovación o "shumpeterianas" es algo que la CEPAL reconoce explícitamente. Vgr, Bielchowsky (2009: 182) o, Sunkel et al (2009).

6 Las consecuentes recomendaciones de política se caracterizarían por "una mayor apertura comercial, impulsada en forma gradual y selectiva y reforzada por un tipo de cambio real elevado y estable, como parte de un proyecto orientado a lograr una competitividad 'auténtica', es decir, basada en el fortalecimiento de la capacidad productiva e innovación" (Bielchowsky, 2009: 179).

7 Según Romo, aunque los neoestructuralistas mantienen términos del viejo estructuralismo, "dejan de lado elementos también fundamentales en el análisis estructuralista. Tal es el caso de la referencia a clases o grupos sociales en el estudio de las desigualdades en la distribución del ingreso o a la dependencia y sus implicaciones en el comercio internacional (...) Sunkel y Zuleta no tienen empacho en señalar que el esfuerzo crítico debe realizarse del lado de la oferta (acumulación, calidad, flexibilidad, combinación eficiente de los recursos productivos) y predican — como los neoliberales — la disciplina social, la frugalidad en el consumo público y privado y el aliento al ahorro nacional" (Guillén Romo, 2007: 312). 
En línea con todo lo anterior entonces señalábamos que, con el análisis de las nuevas transformaciones tecnológicas, parecen haberse aceptado de un modo velado los supuestos más profundos de la teoría liberal en el análisis. Básicamente,

porque de otra manera, y como intentaremos mostrar a partir del análisis específico de los cambios en la industria automotriz argentina, sería imposible sostener en abstracto que el hecho de que grandes empresas trasnacionales hayan decidido trasladar a la periferia segmentos intensivos en mano de obra, constituye una oportunidad para estas últimas.

Desde este trabajo consideramos que esto último sólo puede ser pensado desde un marco donde los cambios en los "paradigmas tecno-productivos" (así se denomina en varios de estos trabajos a las transformaciones a las que hacemos mención) son considerados elementos exógenos en términos político-económicos (Astarita, 2006b), al cual se adaptan o no agentes homologables, potencialmente competitivos. Aunque éstos no sean estrictamente los términos de la literatura, si los agentes ubicados en los distintos países en desarrollo y desarrollados no son potencialmente competitivos (al menos los que no están ubicados en los núcleos técnicos de las cadenas) ${ }^{8}$ es sumamente difícil pensar en la posibilidad de ascenso industrial en los términos abstractos antes mencionados. Es decir, pensar que ciertas empresas individuales ubicadas en países atrasados tendrán la capacidad para ganar espacios en cadenas mundiales de valor a partir de un proceso de aprendizaje organizacional. Aun aceptando esto último, eso no necesariamente significa que podamos inferir que el ascenso industrial puede constituir una estrategia exitosa para todos los países atrasados por igual. De hecho, podemos pensar, como señalan algunos autores críticos (Razmi et al, 2004), que la competencia entre países periféricos tiende a disminuir o anular los efectos "beneficiosos" de la estrategia de segmentación productiva. ${ }^{9}$ Todo lo anterior sin mencionar aun que, como estudiaremos para la industria automotriz argentina, son varias veces los intereses de las empresas trasnacionales que llevan adelante los procesos de fragmentación global de la producción los que son incompatibles con el "aprendizaje" de los agentes de los países en desarrollo, y en este sentido, limitan indudablemente el proceso de innovación local.

8 Cuando hablamos de núcleos técnicos nos referimos a aquellos sectores que imponen tanto los ritmos como las características técnicas de la producción.

9 Pensar que la segmentación productiva constituye una oportunidad para todos los países en desarrollo, constituye un claro ejemplo de falacia de composición; es decir, un razonamiento al que se le atribuye al conjunto características que (posiblemente) son de las partes, sin que medie ninguna necesidad lógica. 


\section{Una interpretación alternativa del problema de la segmentación productiva}

Hasta aquí hemos intentado realizar una brevísima mención de lo que son las transformaciones tras la formación de un nuevo consenso en el pensamiento económico latinoamericano en torno a la problemática del desarrollo. No obstante, existe una gran variedad de autores de diversas raíces teóricas que han intentado formular una interpretación alternativa de dichos procesos, en donde se intenta articular el análisis económico con las categorías y abordajes teóricos que el pensamiento crítico latinoamericano señaló en sus orígenes. Es decir, se trata de un análisis cuyo centro sigue siendo la identificación de clases sociales $\mathrm{y}$ sus intereses detrás de procesos que son considerados históricos, ${ }^{10} \mathrm{y}$ en donde las formaciones económicas centrales y periféricas siguen teniendo especificidades relevantes para el análisis de estas clases y transformaciones. La siguiente cita de E. Arceo (2006: 31) es ilustrativa de lo anterior.

La caída en la tasa de ganancia, que se encuentra en el origen de la crisis del modo de acumulación imperante hasta los años 70 y de su cuadro institucional (Duménil y Lévy, 2000), impulsa a éstas (las grandes empresas con capacidad de operar a escala trasnacional) a deslocalizar hacia la periferia sus actividades más trabajo-intensivas a fin de reducir sus costos (...) La condición de posibilidad para el efectivo ejercicio de esta nueva capacidad del capital trasnacional para desarrollar de manera directa, $\mathrm{o}$ a través de contratos y subcontratos, las distintas fases de un proceso productivo fragmentado espacialmente, es la apertura comercial y financiera de la totalidad de los países. Esto exige la constitución de organismos que, como la omc, regulen el funcionamiento de un mercado mundial único, impulsen la integración a éste de la totalidad de los países y aseguren el libre acceso por el capital al conjunto de las actividades, garantizando la no interferencia de los Estados en su accionar y un adecuado respeto de los derechos derivados de la propiedad intelectual.

Como se observa, el análisis reconoce la transformación cualitativa en el modo de producir mercancías, pero ésta es parte de un proceso histórico y, como tal, es impulsada, y tiene consecuencias por y sobre actores que constituyen este

10 Este tipo de análisis se encuentra en las antípodas de aquellos que suelen hablar de "agentes económicos", en la medida en que entendemos que este último término, de manera velada o explícita, niega las diferencias de distinta índole que existen entre los mismos y que son centrales para entender oportunidades y limites para países en desarrollo. 
proceso específico. Lo relevante de este tipo de análisis es que pretende articular lo que anteriormente habíamos presentado como distintos fragmentos de un proceso complejo de transformaciones económico-políticas (y deberíamos incluir, ideológicas). Es decir, si antes se mencionaba que el cambio en la historia real y en el contexto ideológico es el que obliga a "matizar los énfasis y a renovar las interpretaciones, a fin de adaptarse a los nuevos contextos históricos" (Bielschowsky, 2009); ${ }^{11}$ ahora podemos pensar que el nuevo consenso en torno a la problemática del desarrollo no es sólo una respuesta pasiva frente a un cambio de contexto sino que es una parte activa o funcional a este último.

En relación con lo explicitado al principio de este trabajo, podemos decir que estas transformaciones están relacionadas con la valorización del capital trasnacional. Si a mediados del siglo xx éste se radicó en la periferia latinoamericana con el propósito de abastecer sus respectivos mercados internos, en un proceso que incluía la apropiación de los capitales individuales de una porción de riqueza extraordinaria -asociada a la explotación de recursos naturales-así como la sobreamortización de capital como estrategia de valorización (lo que explicaba parcialmente la baja capacidad de estos sistemas industriales periféricos para exportar sus mercancías), en la actualidad esto se ha modificado (aunque no necesariamente deje de existir en algunos casos). El capital trasnacional tiene la posibilidad de trasladar a la periferia segmentos enteros de las cadenas productivas, utilizando al país receptor exclusivamente como plataforma de exportación en dinámicas que no necesariamente tienen efectos beneficiosos para estos últimos (UNCTAD, 2002). La novedad entonces es que se pueden fabricar en la periferia productos para abastecer mercados centrales con salarios periféricos y tecnología del centro. Ésta es la clave en términos de la mencionada búsqueda de incremento en los márgenes de ganancia, y redefine no sólo el lugar de ciertas industrias en las economías periféricas (en términos de sus efectos multiplicadores y de transferencia tecnológica) sino también las posibles alianzas entre el capital trasnacional y las burguesías nacionales en estas últimas.

En este marco, el tradicional intercambio de productos primarios por manufacturas elaboradas entre periferia y centro respectivamente fue reemplazándose por un proceso complejo donde la periferia interviene también en la exportación de productos elaborados (además de los productos primarios), incluso

11 Otra vez, la interpretación de Bielchowsky es ilustrativa sobre esta cuestión, "Si para algunos ello significó rendirse al neoliberalismo, para otros fue una alternativa que permitiría seguir incidiendo en los destinos de la región desde la perspectiva teórica y metodológica clásica de la CEPAL" (Bielchowsky, 2009: 178). 
aumentando significativamente su participación en la exportación de productos con un alto desarrollo tecnológico. En palabras de Giovanni Arrighi (1997: 188), podemos decir que asistimos "a una división del trabajo donde el centro es predominantemente el lugar de emplazamiento de las actividades cerebrales del capital corporativo y la periferia el locus de los músculos y los nervios”.

Por último, la potencial incompatibilidad de intereses entre el capital trasnacional, cuya estrategia en la periferia latinoamericana pasa en creciente medida por la reducción de costos para la exportación y burguesías nacionales poco estimuladas históricamente a la innovación tecnológica en contextos donde otro era el esquema de desarrollo, es lo que lleva a muchos autores latinoamericanos a cuestionar el "optimismo" al cual la cita de Gereffi hacía mención al comienzo de este trabajo. En palabras de Minian en relación a la cuestión de la segmentación productiva: "(existe) el peligro de dejar a países emergentes sin claras estrategias industriales, atrapados en las etapas de ensamblado, con bajo nivel tecnológico y reducido valor agregado" (Minian, 2009: 3). Para nosotros, la clave entonces es que existe la posibilidad de que los intereses y estrategias de valorización de ciertas fracciones del capital que llevan adelante estos procesos de segmentación productiva, pongan de manifiesto las dificultades en las estrategias de desarrollo industrial de otros actores de los países en desarrollo.

A modo de síntesis, podemos decir que plantear la discusión de si el nuevo escenario de globalización productiva constituye una oportunidad o una limitante a la problemática del desarrollo se nos presenta como una dicotomía que en cierto sentido ha venido a reemplazar las viejas preocupaciones y métodos del pensamiento latinoamericano reintroduciendo supuestos y abordajes de corte abstracto ya superados en gran parte de la región. En este sentido, entendemos que para evaluar las posibilidades del desarrollo de algunas empresas periféricas ${ }^{12}$ en el nuevo proceso de división internacional del trabajo es necesario pensar ciertas cuestiones centrales: $i$ ) el tipo de cadenas productivas en las cuales están insertos los países; ii) la historia de retraso relativo del país y de los sujetos económicos involucrados; y iii) los intereses del capital con capacidad de operar a escala trasnacional que lidera los procesos en dichas cadenas, en relación a su operatoria en cada formación social periférica.

12 Debemos aclarar que el éxito de un determinado grupo de empresas no necesariamente es sinónimo de desarrollo económico. En algún sentido, si bien el neoestructuralismo explicita que el desarrollo económico incluye una dimensión distributiva que no necesariamente está asociada directamente al crecimiento (Bielchowsky, 2009; Sunkel et al, 2009), entendemos que los vínculos entre el "éxito" en los espacios globales de valor y el modo en que esto puede redundar sobre la primera cuestión, es algo aún no demasiado problematizado. 
En pocas palabras, así como no podemos afirmar apriorísticamente que el nuevo proceso de división internacional del trabajo constituya una oportunidad para los países en desarrollo, tampoco podemos decir que sea un límite para todos los sujetos económicos en estos últimos. Lo que sí podemos afirmar es que es imposible reducir la problemática del desarrollo a un conjunto de postulados abstractos en torno a la innovación, que no den cuenta de los conflictos de intereses detrás de un proceso que tiene como fin último de los "agentes" la obtención de ganancias.

Antes de pasar al análisis del sector automotriz argentino, lo que constituye un claro contraejemplo a la idea de "oportunidades para la periferia" en Latinoamérica, nos parece importante realizar una breve mención sobre algunas de las cuestiones que fueron determinantes en el caso del "milagro" del sudeste asiático. Esto obedece al hecho de que este caso suela ser utilizado como ejemplo a seguir por los países latinoamericanos sin tomar en consideración una serie de factores históricoestructurales que dificultan su extrapolación para el caso de América Latina, cuestión que pondrá de relieve la importancia del análisis histórico como herramienta para aprehender las particulares limitaciones de la periferia latinoamericana.

\section{¿QUÉ HA SIDO DE LA PERIFERIA?}

\section{Algunas menciones sobre el "milagro asiático"}

La emergencia de un importante número de empresas radicadas en el sudeste asiático con capacidad de exportar mercancías con elevado contenido tecnológico desde mediados de la década del setenta sorprendió a propios y extraños. Parecía que por fin había llegado el momento para que la periferia superase su condición de satélite del proceso económico mundial y se convirtiese en la forjadora de su propio destino.

Esta percepción dio paso en la literatura a un nuevo conjunto de corrientes teóricas críticas de la teoría neoclásica, como es el caso destacado de los institucionalistas ${ }^{13}$ y los neoschumpeterianos, ${ }^{14}$ que intentaron recabar los sucesos

13 Estos autores rechazaron la idea de la eficiencia como producto puro y exclusivo de las fuerzas de mercado y tomaron al Estado como el decisor casi exclusivo del desarrollo de una economía nacional, ubicando el caso del sudeste asiático como una clara muestra de dicha interpretación al respecto, vgr. Amsdem (1991); Evans (1998); Schneider (1999).

14 Para estos autores, el caso asiático fue un ejemplo de gestación premeditado de un entorno económico y político que permitió a las empresas instaladas en estos países embarcarse en procesos de catching-up (captura de tecnologías del centro) para posibilitar el despliegue de desarrollos tecnológicos y feedbacks al interior de dichas economías en el marco de las cadenas globales de producción (vgr. Freeman y Soete, 1997; Ernst, 2004). 
acaecidos en el este de Asia para elaborar un conjunto de "recetas para el desarrollo" a seguir por los países periféricos. Lo importante de estas elaboraciones es que constituyen el fundamento de gran parte de las transformaciones teóricas mencionadas en los apartados anteriores, y por ende, de muchas de las recomendaciones de política pública latinoamericana. ${ }^{15}$

¿Pero puede el caso asiático ser extrapolable al caso latinoamericano? ¿En qué medida esas "rectas" pueden tomarse de manera abstracta? A nuestro modo de ver, el caso asiático aparece como el ejemplo que corrobora la regla, en un modo de razonamiento que por su abstracción no tiene en cuenta las especificidades de un caso histórico difícilmente extrapolable a otras realidades periféricas. ¿En qué medida podemos saber que determinadas políticas de estímulo a la innovación tecnológica tendrán los mismos (o similares) efectos en Latinoamérica cuando su historia, la del conjunto de sujetos intervinientes ( $y$ los sujetos en si), y el momento en el cual estas políticas se aplican, difieren sustancialmente del caso que tomamos como ejemplo? Si bien por su complejidad y el espacio aquí disponible, el caso del sudeste asiático es inabordable en este trabajo, sí consideramos necesario aunque sólo se mencionen aquellos elementos que constituyen un claro contrapunto con la realidad latinoamericana y, en este sentido, que nos alertan sobre los límites de la comparación.

\section{La importancia del momento histórico del desarrollo capitalista $y$ de las caracteristicas de las formaciones sociales periféricas}

Quizás el primer y más importante dato para pensar desde Latinoamérica la experiencia asiática de desarrollo se relacione con cómo ésta estuvo condicionada desde sus inicios por la falta de recursos naturales exportables. Esto no sólo obligó a las autoridades estatales a pensar en un proceso industrial orientado desde sus orígenes al mercado externo (que permitiera financiar las necesidades del desarrollo), sino que estuvo ligado al fortalecimiento de un sector empresario comprometido con el proceso industrial. En palabras de E. Arceo (2006: 45):

15 Según Romo, por diversas cuestiones la experiencia asiática motivó gran parte de las búsquedas teóricas del neoestructuralismo: "en el mismo momento en que los países latinoamericanos en ajuste estructural padecen un fuerte estancamiento, que llevó a hablar de una década perdida, las economías asiáticas alcanzaban tasas de crecimiento sin precedente y lograban mejorar su inserción internacional gracias a sus exportaciones de productos intensivos en nuevas tecnologías. La experiencia asiática constituía una auténtica denegación de las prácticas imperantes en materia de política económica en América Latina” (Guillén Romo, 2007: 307). 
La escasez de recursos naturales determinó, junto con las funciones que cumplió la región en las anteriores fases del desarrollo capitalista, que tuviera uno de los menores ingresos per cápita (y retribuciones al trabajo). Esto le permitió encarar un crecimiento basado en las exportaciones de manufacturas... el aprovechamiento de esta posibilidad fue facilitado por la estrechez del mercado interno, que generaba escasas posibilidades para la sustitución de importaciones, y la ausencia de un flujo significativo de exportaciones primarias susceptible de sostener un proceso de industrialización centrado en el mercado interno.

A su vez, la particular historia de la clase trabajadora asiática, ${ }^{16}$ y la "previsibilidad" que ofrecían aparatos estatales sumamente autoritarios, convirtieron a algunos de los países de la región (Japón fundamentalmente) en pioneros en materia de segmentación internacional de la producción. En el marco de una gran resistencia por parte de la clase trabajadora europea para impedir reducciones salariales (Arceo, 2006b) en los comienzos de la guerra fría, el capital trasnacional trasladaría procesos de producción simples desde Europa hacia aquellos países que, basados en salarios bajos, les permitieron ahorrar costos (Frobel et $a l, 1980)$. Así, fue en Japón donde en un primer momento se inició la producción de los componentes electrónicos necesarios para poner en marcha la

16 La clase trabajadora asiática poseía algunos rasgos particulares que la diferenciaban de la de otros países de la periferia, y que fueron claves en la elección de la región por parte del capital europeo. No sólo era numerosa sino acostumbrada a una historia de sometimiento colonial en la producción agrícola en escala que, en el marco de un consumo relativamente limitado de bienes para su reproducción y de marcado disciplinamiento, se encontraba en condiciones de ser empleada por salarios bajos en empresas de gran tamaño (Astarita, 2006b; Arceo, 2006). Por otra parte, esta cuestión del disciplinamiento de la clase trabajadora en estos países, que se inscribe en términos más generales en el carácter autoritario que tuvieron los procesos políticos que dieron lugar (en general) a las experiencias de "éxito" asiático, es otro de los elementos que muchas veces es dejado de lado a la hora de valorar este tipo de casos. Y si bien, como decíamos al inicio de estos párrafos, el objetivo de este trabajo no es analizar en profundidad los mismos, consideramos que es un elemento más a la hora de pensar en las dificultades de una posible comparación entre las experiencias asiáticas en general, y las latinoamericanas.

En el caso de África, si bien allí habitaban numerosos trabajadores disponibles que podían ser empleados a salarios reducidos, la producción agrícola se había desarrollado de manera descentralizada y no se habían presentado indicios de industrialización. En América Latina, el proceso de industrialización por sustitución de importaciones, si bien tuvo una serie de fuertes limitaciones, permitió, en algunos casos como el argentino, un grado de acumulación de capital compatible con una clase trabajadora organizada y bien remunerada en términos relativos latinoamericanos. 
automatización y, en un segundo momento, se iniciaron procesos de investigación y desarrollo de tecnologías al interior del ámbito nacional (Gore, 1994).

El desarrollo de la industria japonesa permitió la inserción progresiva de distintos países del este de Asia en el desarrollo de procesos de producción simple que Japón abandonaría. Como seńala E. Arceo (2006: 44):

La expansión de Malasia, Tailandia, Indonesia y restantes economías del este asiático está ligada en mucho mayor medida al desarrollo de las inversiones de las grandes empresas japonesas, que ya habían jugado un papel importante en la transmisión de tecnología a Corea y Taiwán a través de la venta de licencias y asociaciones permanentes o transitorias con empresas locales, donde aceptan tener una posición minoritaria.

La clave, a nuestro modo de ver, estriba en que, a diferencia de lo ocurrido en América Latina, las transformaciones tecnoproductivas que dieron lugar a esta etapa de internacionalización del capital encontraron en gran parte del sudeste asiático una red de empresarios que ya estaban organizados a escala regional en la producción de manufacturas electrónicas diseñadas para la exportación. Esto fue determinante a la hora de insertarse en estos nuevos espacios globales de valor. Como intentaremos mostrar a partir del análisis de caso de la industria automotriz argentina, en América Latina (en los casos en que lo hubo) el proceso de industrialización "cerrado", pensado para abastecer a los respectivos mercados internos, y posibilitado en parte por los ingresos derivados de los recursos naturales exportables, condicionó de un modo muy distinto las posibilidades de éxito de los empresarios locales frente a la apertura de los mercados y el cambio en las escalas de producción y comercialización del capital trasnacional.

En resumidas cuentas, la historia latinoamericana es sustancialmente distinta a la de los países asiáticos, lo que nos impediría pensar mecánicamente en la extrapolación de políticas públicas. El gran capital latinoamericano nunca se desvinculó de sus negocios en el sector primario (lo que de hecho explica que pocas veces haya estado realmente comprometido con los procesos de industrialización en la región), y la pequeña burguesía local siempre fue dependiente de una fuerte protección estatal y de los intereses más generales del capital trasnacional, lo que, como intentaremos problematizar, es posible que haya condicionado de un modo sumamente distinto al asiático sus posibilidades de inserción exitosa en el nuevo escenario internacional.

No obstante lo mencionado, debemos decir que la incorporación al proceso productivo industrial de Corea así como de otros países del sudeste de Asia como Malasia, Singapur, Tailandia, Taiwán no fue puramente virtuosa. 
De hecho, no son pocos los autores que ven en la década del noventa, y en las fuertes necesidades por parte de estos países de recurrir al endeudamiento externo para profundizar el proceso industrializador, un síntoma claro de sus limitaciones (Perraton, 2002). En este sentido y siguiendo con el análisis de fines del apartado anterior, es interesante observar que, pese a haber desarrollado una importante red de empresarios exportadores, los 5 países de nueva industrialización del sudeste asiático antes mencionados, ${ }^{17}$ no parecen haber logrado apropiarse de manera concomitante de una parte cada vez más significativa del valor generado en los nuevos espacios globales (en línea con la cita de Gereffi antes mencionada). En efecto, según los datos de la un Commtrade, los cinco países asiáticos mencionados han incrementado sus exportaciones de manufacturas de alto contenido tecnológico en más de un $6000 \%$ (en dólares corrientes) entre 1981 y 2006, pero no han logrado un incremento paralelo en su participación en el valor agregado mundial. Así, si en el primero de los años éstas representaban una porción minúscula del comercio mundial, para el año 2006 dichos países se habían transformado en uno de los principales centros exportadores mundiales de productos intensivos en tecnología. ${ }^{18}$

Sorpresivamente, esto no ha tenido como correlato un aumento en la participación de la región en el producto bruto mundial. De hecho, según los datos del Fondo Monetario Internacional, ésta se mantuvo prácticamente constante entre puntas, en torno al 2\%, con una leve disminución durante los años que van de 1995 al 2006.

\section{Las transformaciones en la industria automotriz argentina Un análisis de caso en la periferia latinoamericana}

Pasemos finalmente al análisis de un caso de la periferia latinoamericana. Como señalamos algunos apartados atrás, el análisis de las transformaciones recientes en la industria automotriz argentina resulta relevante a los fines de este trabajo por varios motivos. En primer lugar, porque la producción de automóviles es

17 Son quienes han evidenciado un mayor éxito en el desarrollo de una industria orientada a la exportación de manufacturas de alto contenido tecnológico.

18 Para 1981 los 5 países asiáticos mencionados representaban el equivalente al 3\% de las exportaciones de alto contenido tecnológico de Europa y Estados Unidos juntos; para el 2006, su participación ascendía al 25\%. En dicho año además, el 40\% de sus exportaciones totales eran manufacturas con un alto contenido tecnológico. 
uno de los ejemplos paradigmáticos de la literatura sobre segmentación internacional de la producción. En segundo lugar porque, como intentaremos mostrar, tanto antes como hoy la producción de automóviles ha sido uno de los principales motores del crecimiento industrial. Y por último, porque la Argentina es considerada por el neodesarrollismo como uno de los países de ingresos medios en la región más capacitados para aprovechar las ventajas del nuevo contexto de segmentación global de la producción (Bresser-Pereira, 2007).

\section{Las transformaciones en la producción de automóviles}

En Latinoamérica, desde fines de los ochenta, tras lo que la literatura señala como el agotamiento del esquema de sustitución de importaciones, las principales empresas trasnacionales ubicadas en el segmento terminal de dicha industria comenzaron un proceso de renovación en las plataformas de ensamble que supuso dos cambios principales en sus procesos de producción. Por un lado, se incrementaron significativamente los parámetros de productividad por obrero ocupado en dicho segmento, hasta alcanzar niveles cercanos a los de países desarrollados (Santarcángelo y Pinazo, 2009). Por el otro, se inició un proceso de estandarización regional de la producción que redundó en una redefinición de las estrategias en términos de aprovisionamiento de autopartes y comercialización de productos terminados, que unió el mercado del cono sur americano y redujo significativamente el número de autopartistas encargados de la provisión de insumos.

Pero esto último no es una tendencia exclusiva de Latinoamérica. A nivel mundial, las empresas terminales han relegado un número cada vez más importante (tanto en número como en complejidad) de actividades a empresas autopartistas, muchas de las cuales han comenzado a operar a escala trasnacional. Nuevamente, en sintonía con la cita de Arrighi del apartado anterior, las terminales han reducido su accionar a actividades de diseño, ensamble y comercialización, y las autopartistas han pasado a ocuparse de la fabricación de módulos o subensambles enteros, como ser el armado de motores, sistemas de aceleración, frenos o dirección. Esto ha permitido a las terminales reducir significativamente el número de empresas autopartistas con el que se relaciona, y a un número reducido de éstas, encargarse del diseño, la manufactura y la entrega de ensambles tecnológicamente cada vez más sofisticados (Gereffi, 2001; Cantarella et al, 2008).

Esta reestructuración del proceso productivo, especialmente en regiones como la latinoamericana ha redefinido y profundizado la jerarquía de empresas que participan en la cadena de producción de automóviles. En Argentina 
especialmente, las empresas nacionales que producían en el viejo esquema de sustitución de importaciones fueron relegadas a la producción para el mercado de reposición (o desapareciendo, en algunos casos), y las empresas terminales pasaron a abastecerse de empresas trasnacionales con las cuales, con sede o no en la Argentina, tienen una relación que excede al país en cuestión. Así, el universo de empresas autopartistas en la Argentina tendió a quedar consolidado en dos grandes grupos: el de empresas trasnacionales que, proveyendo a las terminales, exhiben en muchos casos una lógica de operatoria trasnacional y parámetros productivos de frontera (Motta et al, 2007), ${ }^{19} \mathrm{y}$ el mayoritario resto, dedicado fundamentalmente al mercado de reposición

\section{Las oportunidades del empresariado argentino: la importancia de la mirada histórica}

Como señaláramos anteriormente, entendemos que la industria automotriz argentina constituye un claro contraejemplo a las tesis "optimistas" sobre el problema de globalización productiva. Según lo que pudimos observar, desde este último tipo de enfoques el ascenso industrial podría ser interpretado, en el caso de esta industria en particular, como la capacidad de los agentes ubicados en el segmento autopartista de desarrollar actividades cada vez más complejas, en una dinámica que las acercara de manera creciente a la provisión de equipo original para las empresas trasnacionales ubicadas en el segmento terminal. Pero si prestamos un poco de atención a la historia del segmento autopartista en Argentina (y particularmente al momento específico en que comienzan a producirse cambios en las escalas de producción y comercialización liderados por las empresas trasnacionales), atendiendo a los tres ejes tratados en el final del apartado anterior, encontraremos que el concepto de ascenso industrial aplicado a este caso no puede existir más allá de las construcciones teóricas.

Esquemáticamente, podemos señalar que es en el modo complejo en que la Argentina llevó a cabo su estrategia de desarrollo por sustitución de importaciones a mediados del siglo $\mathrm{xx}$, donde deben rastrearse las raíces de la profunda dificultad que experimentan en la actualidad los empresarios del segmento autopartista local por encarar procesos "virtuosos" de inserción en las nuevas cadenas

19 En Argentina, "la producción de autopartes presenta una elevada concentración, lo que se refleja en que el 30\% de las empresas explican el 70\% de la facturación del sector. También las exportaciones se encuentran concentradas en las empresas líderes del sector", Motta et al (2007: 239). 
globales de la industria. En efecto, y paradójicamente, fue la particular estrategia del capital trasnacional durante dicho periodo tanto lo que permitió el desarrollo del sector autopartista, como el que condicionó de un modo profundo ${ }^{20}$ su estancamiento posterior.

El capital trasnacional se radicó en el país a principios de los sesenta atraído por una particular ley de promoción a la inversión extranjera y una serie de estímulos a la producción local de bienes de consumo durable. Para el Estado, la atracción del capital extranjero era el mejor modo para superar los cuellos de botella externos de la primera fase del desarrollo industrial sustitutivo (19431958) (Mallon et al, 1973), y de desarrollar actividades que, sin su participación, se diagnosticaban como sumamente complejas. Para el capital extranjero, la fuerte protección que suponían las leyes de estímulo, ${ }^{21} \mathrm{y}$ la enorme brecha de demanda insatisfecha que ofrecía el mercado argentino, significaron la posibilidad, entre otras cosas pero fundamentalmente, de sobreamortizar capital cuasi obsoleto en términos de sus países de origen.

El sector automotriz fue uno de los centros más importantes donde éste se radicó durante el largo periodo de desarrollo sustitutivo, y su crecimiento supo motorizar a una parte más que importante del resto de la estructura económica, en el periodo de mayor crecimiento con bienestar social que recuerde la historia argentina. No sólo la producción final trepó de 32 mil unidades en 1959 a 215 mil en tan sólo diez años, sino que, gracias a la particular estrategia de integración nacional de la producción, se fabricaron en el país desde blocks para motor, pasando por cajas de cambio, sistemas de freno y toda una serie de artículos de interiores. El sector autopartista era el vínculo entre el "sector moderno" de la economía argentina, el segmento terminal de la industria automotriz, y las industrias del acero, el caucho, el plástico y otras tantas. Las palabras de Sourrouille (1980: 91) son elocuentes en relación al lugar que supo ocupar el sector, "la industria terminal es el mercado final para casi todos los sectores en los que se ha englobado la actividad económica interna”. Ahora bien, la contracara de este esquema fue el desarrollo de un contexto de escaso estímulo a la innovación tecnológica. Así, mientras en países desarrollados las empresas autopartistas se constituían en los pilares del progreso técnico del conjunto de la cadena automotriz, en Argentina

20 Al mencionar los límites para el desarrollo del sector autopartista asociados a su historia de retraso relativo, no pretendemos negar las políticas de desindustrialización aplicadas en Argentina, que no pueden explicarse exclusivamente por motivos "técnicos".

21 "Se garantizaba la liberación de aranceles a la importación de bienes de capital que no se producían en el país, la protección arancelaria o suspensión de importaciones de bienes competitivos" (Santarcángelo y Pinazo, 2009: 41). 
su supervivencia dependió de la decisión de pocas empresas extranjeras que, en contextos de fuerte protección, poca intención tenían de seguir los estándares internacionales en la materia. ${ }^{22}$

Este brevísimo repaso está pensado para poner en contexto los potenciales peligros que los empresarios de países periféricos pueden enfrentar frente a esta nueva globalización productiva en función de su historia previa que, como podemos apreciar, en el caso argentino parecer ser la contracara de lo sucedido en países que han sido tomados como ejemplo a seguir.

La modificación drástica de las estrategias de valorización de las empresas trasnacionales del segmento terminal, a partir de la adopción de escalas trasnacionales y/o regionales con respecto al abastecimiento de insumos, obligó al grueso del empresariado autopartista local, acostumbrado a abastecer terminales "poco estimuladas" a la innovación tecnológica, a competir con mercados mucho mayores y desarrollados como el brasileño, en un momento de la historia argentina de significativa reducción de aranceles y cupos a la importación, y de apreciación del tipo de cambio real inédita en su historia reciente..$^{23}$

En este escenario, varios trabajos de principios de los noventa señalaban que la integración regional de las empresas terminales tendría consecuencias negativas sobre el empresariado argentino difíciles de revertir en el tiempo (Kosacoff et al, 1991: 45-46), y que de ninguna manera podía pensarse que su éxito o fracaso dependiese de la capacidad de agentes individuales (Varela, 2003: 126). Se señalaba que una vez que la "nueva industria" está consolidada, es difícil que, dados los niveles necesarios de inversión, el poder de decisión de las terminales (y su vinculación directa con un número reducido de autopartistas) y los riesgos de la competencia, el agente nacional puede desarrollar las competencias necesarias para ganar espacios en la cadena de producción automotriz. ${ }^{24}$

22 "Tanto la enorme capacidad ociosa con la que operó la industria durante todo el periodo (estimada en alrededor del 30\%, tanto de la industria terminal como autopartista para 1967, según ADEFA), como la sobreabundancia de modelos en función del tamańo del mercado (Parellada, 1970), o la relación entre los costos locales de producción y los internacionales (aproximadamente dos veces y medio según las estimaciones de Sourrouille), dan cuenta de las profundas limitaciones que exhibía el esquema” (Santarcángelo y Pinazo, 2009: 49). El tipo de cambio real era en 1994 alrededor de un 40\% del valor del quinquenio 1986-1990.

24 Las siguientes palabras de Minian (2009: 21, énfasis propio) parecen pensadas para el caso argentino frente a los peligros de la competencia brasileńa: "aún más complejos son los problemas que enfrentan los países que intentan insertarse en un patrón de especialización más avanzado. No sólo los requerimientos de inversión, de tecnología, de capital humano y de nuevas instituciones son exigentes, sino que a ello se agrega las dificultades que surgen de la existencia de países de nueva industrialización ya consolidados en este nuevo paradigma". 


\section{El segmento terminal de la industria automotriz argentina hoy: mano de obra barata y exportación}

El caso de las transformaciones en el segmento terminal de la industria automotriz argentina parece ajustarse perfectamente a la interpretación crítica que planteáramos algunos apartados atrás. La renovación en las plataformas de ensamble ha redundado, como muestran los gráficos que siguen, en incrementos exponenciales en los parámetros de productividad laboral, en un contexto en el que los salarios son relativamente bajos en relación a los estándares internacionales. Así, las empresas trasnacionales tienen la posibilidad de utilizar la plaza argentina casi exclusivamente como una plataforma de exportación, a partir de la estandarización de los productos y la importación de subensambles enteros. Esto permite comprender la disociación creciente entre el desempeño de la producción terminal y la autopartista (Cuadro 1), y los inéditos indicadores de exportaciones en relación con los valores brutos de producción del primer segmento (Gráfica 1).

Los datos son sumamente ilustrativos: el número de automóviles por obrero ocupado por año ha crecido un $79 \%$ entre 1990 y 2007 . Esto significa que en la Argentina un trabajador llegó a producir en 2007 alrededor de 24 automóviles anuales, es decir, 6 más que en Corea del Sur (la coreana es una de las seis industrias automotrices más grandes del planeta) y casi lo mismo que en Brasil (la más grande de Latinoamérica). En contrapartida, el salario horario medio de un trabajador en Argentina era, en ese año, apenas un $40 \%$ del de Corea, ${ }^{25}$ y casi cuatro veces menos que el de Estados Unidos. En un contexto donde los vehículos se han convertido en productos estandarizados a nivel mundial, y los costos de transporte han descendido significativamente, esto permite comprender el inédito salto que exhiben las exportaciones.

Lo interesante del Cuadro 1 es que muestra que a lo largo de ese periodo (1991-2009) el peso de los insumos importados en el consumo nacional de autopartes se incrementó notablemente, aun en el contexto actual de tipo de cambio depreciado en términos reales, y de un considerable número de políticas de estímulo al sector. ${ }^{26}$ Es decir, aun en contextos que parecerían favorables para el ascenso industrial, el peso de las cuestiones estructurales de una industria consolidada en torno a los intereses de un reducido número de capitales trasnacionales

25 Surge de la comparación entre los datos de ADEFa y la Oficina de Estudios Laborales de EeUU.

26 Créditos a tasas diferenciales subsidiados por el Estado para la compra de autopartes nacionales, por ejemplo. 
Gráfica 1. Segmento terminal. Peso de las exportaciones en el valor bruto de producción, producción final anual y productividad por obrero ocupado por año

1959-2007

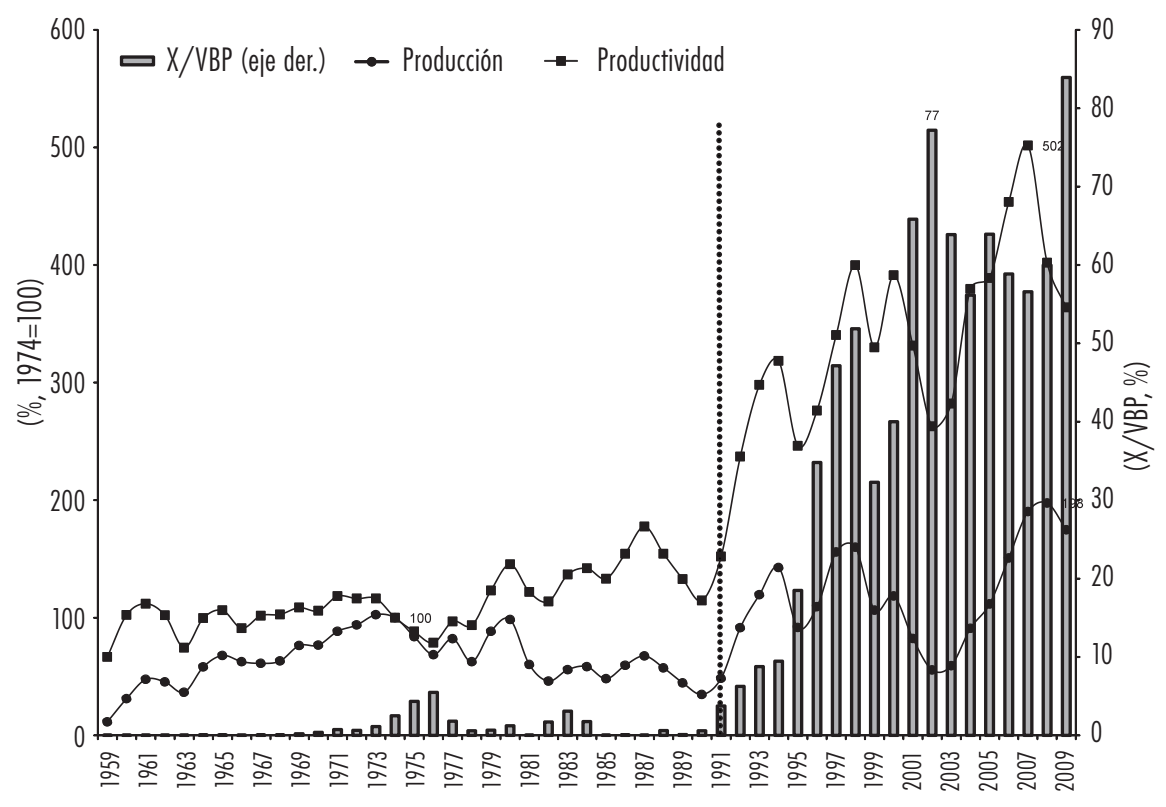

Fuente: Elaboración propia sobre la base de ADEFA, CEP (2010) y Barbero (2007).

parece ser el factor clave para pensar las posibilidades de desarrollo de un debilitado número de capitales periféricos. Ahora bien, lo importante de esta dinámica es que el sector autopartista ha sido históricamente, y aún lo es, el vínculo excluyente entre el segmento terminal de la industria automotriz y el resto de la estructura económica. ${ }^{27}$ En este sentido, la (des)vinculación con dicho sector no sólo es un elemento clave a la hora de tener en cuenta posibles efectos de transferencia tecnológica sobre el resto de los empresarios argentinos, sino que es central para entender los efectos cada vez menores que el crecimiento del sector automotriz tiene sobre la generación de empleo en nuestro país.

27 Para 1991 se estimaba que el 46\% de las compras del segmento terminal estaba orientado al sector autopartista, mientras que ningún otro sector superaba el 5\% de las mismas (Kosacoff, et al, 1991: 19). 


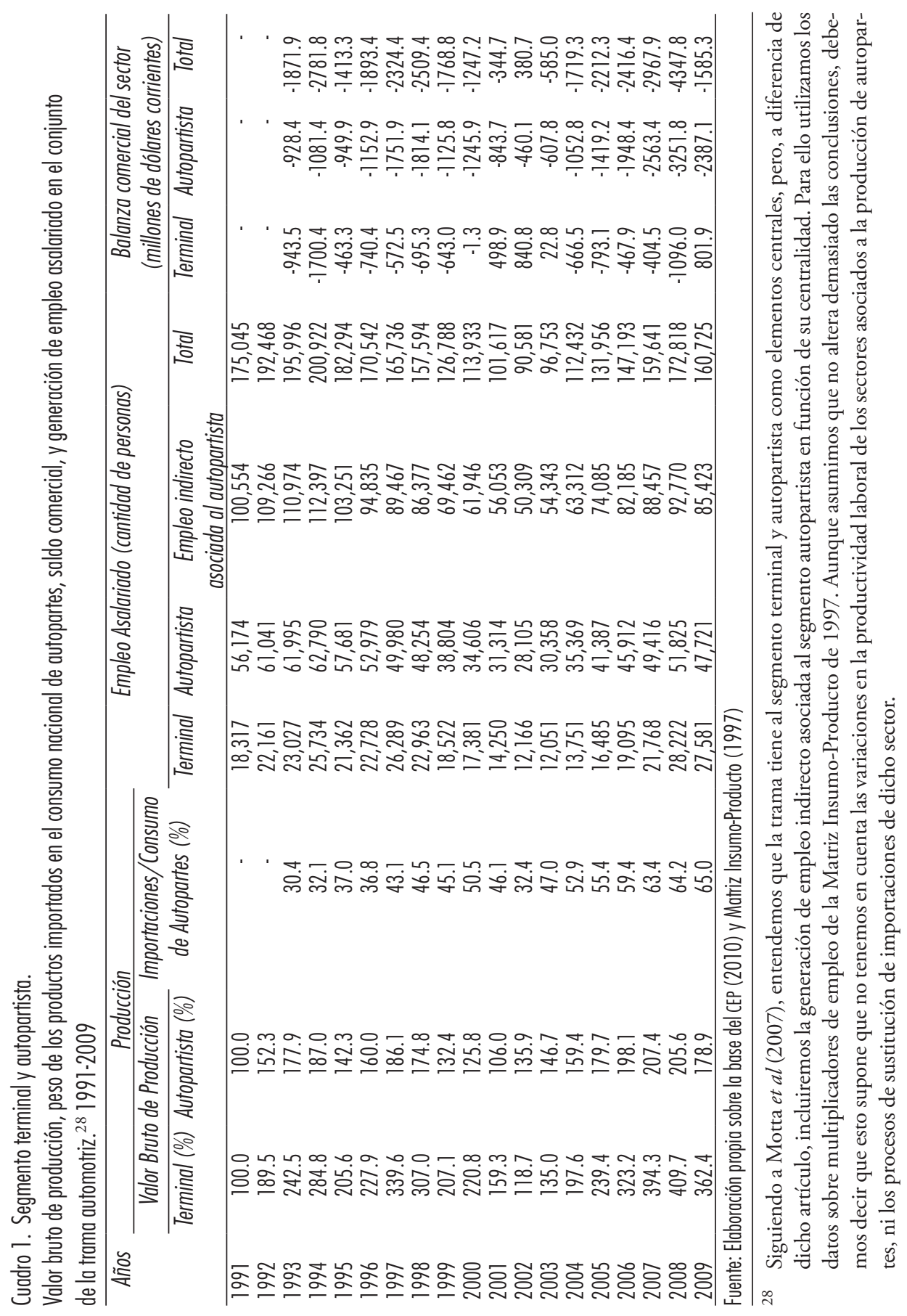


Como vemos, en momentos en que se registran año a año récords históricos en materia de producción final de automóviles, y donde la industria en su conjunto es cada vez más significativa en términos del PBI, ${ }^{29}$ la trama ha disminuido significativamente su aporte al empleo asalariado, en un proceso íntimamente vinculado a la disociación observada de los valores de producción. En efecto, lejos de ser el significativo aumento de la productividad laboral en el segmento terminal el factor determinante a la hora de comprender dicha disminución, es la desvinculación con el segmento autopartista local (a raíz tanto de su aporte directo al empleo asalariado, pero fundamentalmente de su aporte indirecto) lo que explica la significativa caída. Por otro lado, la posición subordinada de la industria argentina en el actual proceso de segmentación global de la producción automotriz ha presionado significativamente sobre la balanza comercial, dado el creciente peso de las importaciones en el armado final de automóviles. De hecho, es probable que dicha presión hubiese significado una seria restricción externa al crecimiento, de no ser por la inédita situación de los precios internacionales de los productos agroindustriales. ${ }^{30}$

En resumidas cuentas, la industria automotriz argentina en la actualidad parece más una actividad de enclave (que en lugar de aprovechar la productividad diferencial de los recursos naturales, aprovecha el precio relativamente barato de la fuerza de trabajo) que una actividad que pueda contribuir a un proyecto de desarrollo, en cualquiera de los sentidos con que se ha utilizado la palabra en este trabajo.

\section{ALGUNOS COMENTARIOS A MODO DE CONCLUSIÓN}

Como señaláramos en la introducción, el objetivo principal de este trabajo es el de mostrar la importancia de pensar la problemática del desarrollo y sus condicionantes en América Latina desde una perspectiva histórica. A nuestro entender, a partir del progresivo abandono y reemplazo por una serie de recetas

29 Según el Estimador Mensual Industrial, publicado por el Instituto Nacional de Estadística y Censos, la "nueva" industria automotriz exportadora ha explicado el 31\% del crecimiento de la industria manufacturera entre 2003 y 2008, siendo en 2003 apenas el 5\% del PBI industrial.

30 En 2008, último año antes de la crisis internacional, el déficit de los segmentos terminal y autopartista de la industria automotriz fue un $102 \%$ superior al del sector industrial en su conjunto. 
abstractas para todos los países periféricos por igual, una parte importante del pensamiento heterodoxo latinoamericano ha incorporado (a veces de un modo más velado y otras más explícito), varios de los supuestos teóricos del neoliberalismo que antes eran eje de su crítica. En este sentido, entendemos que detrás de la creciente atención que se le otorgó a la idea del "agente innovador" como motor del desarrollo, es posible detectar un progresivo abandono de estudios que hagan foco en las clases sociales (o fracciones de las mismas) y sus intereses. Y justamente lo que intentamos mostrar a lo largo del trabajo es que este tipo de análisis y sus condicionantes históricos son centrales para comprender las consecuencias de determinadas transformaciones sobre las formaciones sociales periféricas.

Por último, si una conclusión surge de este trabajo, es que el análisis histórico hace emerger, inexorablemente, la ineludible importancia de la dimensión política en el marco del problema del desarrollo latinoamericano; la que, en un contexto de profundas transformaciones ideológicas en la región, pareció quedar relegada en los espacios del debate académico. Esta dimensión política supone dejar de entender el desarrollo económico como un proceso técnico, neutro de intereses -donde es el progreso de la razón el que marca el camino y donde no es necesario cuestionar la mayor parte de los intereses constituidos- para comenzar a reconocer en su integridad las posibilidades y límites de transformación política de la realidad económica de Latinoamérica.

\section{BIBLIOGRAFÍA}

Amsden, Alice, "Diffusion of Development: The Late-Industrializing Model and Greater East Asia", American Economic Review vol. 81 No 2, 1991, pp. 282-286.

Arceo, Enrique, "El impacto de la globalización en la periferia y las nuevas y viejas formas de la dependencia en América Latina", en Cuadernos del Cendes $\mathrm{N}^{\circ}$ 60, Venezuela, septiembre-diciembre 2005 (consultado el 10 de noviembre de 2010), disponible en <http://www.cendes-ucv.edu.ve/pdfs/Arceo $\% 20$ 25-61.pdf >

, "El fracaso de la reestructuración neoliberal en América Latina.

Estrategias de los sectores dominantes y alternativas populares", en Basualdo, Eduardo y Enrique Arceo, Neoliberalismo y sectores dominantes. Tendencias globales y experiencias nacionales, ClACso, Buenos Aires, agosto 2006, pp. 27-65.

Arrighi, Giovanni, A ilusao do desenvolvimiento, Petrópolis, Editora Voces, 1997. 
Astarita, Rolando, Valor, mercado mundial y globalización, Editora Kaicron, 2006.

, "Neoschumpeterianos y marxismo". Notas de clase, 2006 (consultado el 10 de noviembre de 2010), disponible en <www.rolandoastarita. com.ar>

"Institucionalismo y marxismo". Notas de clase, 2006b (consultado el 10 de noviembre de 2010), disponible en <www.rolandoastarita. com>

Barbero, María Inés y Jorge Motta, "Trayectoria de la industria automotriz en la Argentina desde sus inicios hasta finales de la década de 1990", en Delfíni, Marcelo, Daniela Dubbini y Manuel Lugones (comp.), Innovación y empleo en tramas productivas de Argentina, Prometeo-ungs, 2007, pp. 189-229. Bielschowsky, Ricardo, "La evolución de las ideas de la CEPAL" en Revista de la CEPAL, número extraordinario, octubre 1998, pp. 21-45.

, "Sesenta años de la CEPAL: estructuralismo y neoestructuralismo, en Revista de la CEPAL, No 97, 2009, pp.173-194.

Bresser-Pereira, Luiz, "Estado y mercado en el nuevo desarrollismo", en Nueva Sociedad, No 210, 2007, pp.110-125.

Cantarella, J., L. Katz, G. Guzmán, "La industria automotriz argentina: limitantes a la integración local de autocomponentes", marzo 2008 (consultado el 10 de noviembre de 2010), disponible en <http://www.littec.ungs.edu.ar/ pdfespa\%F1ol/DT\%2001-2008\%20Cantarella-Katz-de\%20Guzman.pdfs Casparrino, Claudio. "Nuevos dilemas del desarrollo periférico: notas sobre la heterodoxia conservadora, democracia y cambio social", la revista del CCC (en línea), $\mathrm{N}^{\circ} 4$, septiembre-diciembre 2008.

disponible en www.centrocultural.coop/revista/articulo/87/. ISSN 1851-3263

Centro de Estudios para la Producción (2010), "Fichas Sectoriales 2009”, 2009 (consultado el 10 de noviembre de 2010),

disponible en <http://www.cep.gov.ar/web/index.php?pag=68>.

Evans, Peter y Paulo Bastos, "Going Beyond Clones in Brasil and Korea" en World Development vol. 17, N 11, noviembre 1989, pp.1751-1768.

Freeman, Chris y Luc Soaete, The Economics of Industrial Innovation, Cambridge Massachussets, мiт Press, 1997.

Frobel, Folker, Jurgen Heinrichs y Otto Kreye, La nueva división internacional del trabajo. Paro estructural en los paises industrializados e industrialización de los paises en desarrollo, Siglo xxI editores, México.

Gereffi, Gary, "Las cadenas productivas como marco analítico para la globalización" en Problemas del Desarrollo, Vol. 32, No 125, México, IIEc-unam, 2001, pp. 9-37. 
González Gómez, Ovidio, "Sistemas productivos locales en cadenas mundializadas de valor en América Latina. Alcances y límites”, junio 2009 (consultado el 10 de noviembre de 2010), disponible en <http://lasa.international.pitt.edu/ members/congresspapers/lasa2009/files/GonzalezGomezOvilio.pdf>

Gore, Charles, "Development Strategy in East Asian Newly Industrializing Economies: the Experience of Post-war Japan”, 1953-73", en UNCTAD, Discussion Papers, Nº 92, Geneva, 1994.

Guillén Romo, Héctor, "De la orden cepalina del desarrollo al neoestructuralismo en América Latina”, en Revista Comercio Exterior, Vol. 57, 2007, pp. 295-313.

Kaplinsky, Raphael, "Globalization, and Unequalization; What Can be Learned from Value Chain Analysis?” en Journal of Development Studies, Vol. 27, ${ }^{\circ}$ 2, Cambridge, 2005, pp. 117-146.

Kosacoff, Bernardo, Jorge Todesca y Adolfo Vispo, "La transformación de la industria automotriz argentina”, DT, No 40, CEPAL, 1991 (consultado el 10 de noviembre de 2010), disponible en <http://www.cepal .org.ar/publicaciones/xml/5/22325/40\%20transf\%20indus\%20automotriz.pdf>

Mallon, Richard y Juan Sourrouille, La politica económica en una sociedad conflictiva. El caso argentino, Amorrortu Editores, Buenos Aires.

Minian, Isaac, "Nuevamente sobre la segmentación internacional de la producción” en Economía, unAm, Vol. 6, No 17, 2009, pp. 46-68.

Motta, Jorge, Sonia Roitter, Marcelo Delfíni, Gabriel Yoguel y Darío Miles, "Articulación y desarrollo en la trama automotriz argentina: morfología, innovación y empleo", en Delfíni, Marcelo, Manuel Lugones e Ivana Rivero (comp.), Innovación y empleo en tramas productivas de Argentina, PrometeoUNGS, 2007.

Nahon, Cecilia, Corina Rodríguez y Martín Schorr, "El pensamiento latinoamericano en el campo del desarrollo del subdesarrollo: trayectoria, rupturas y continuidades", en Crítica y teoría en el pensamiento social latinoamericano, CLACSO, 2006, pp. 327-388.

Razmi, Arslan y Robert Blecker, The Limits to Export-led Growth: an Empirical Study, American University, 2004, disponible en

$<$ http://w w.newschool.edu/scepa/events/papers/workshop/razmi_blecker_200405.pdf>

Santarcángelo, Juan y Germán Pinazo, "Análisis crítico de la reindustrialización en la posconvertibilidad: una mirada desde el sector automotriz", en Revista Realidad Económica, N²47, IADE, Buenos Aires, 2009, pp. 38-61.

Schneider, Benr, "Las relaciones entre el Estado y las empresas y sus consecuencias para el desarrollo: una revisión de la literatura reciente" en Desarrollo Económico Vol. 39, № 153, abril-junio 1999, pp. 45-77. 
Sourrouille, Juan, El complejo automotor en la Argentina, Eudeba, Buenos Aires, 1980.

Sunkel, Óscar y Ricardo Infante, Hacia un desarrollo inclusivo: el caso de Chile, CEPAL, OIT, 2009.

Sztulwark, Sebastián, El estructuralismo latinoamericano, Ediciones PrometeoUNGS, 2005.

Varela, Liliana, "El sector automotriz argentino" en Revista Realidad Económica, No 196, IADE, Buenos Aires, 2003, pp. 120-146. 